\title{
Molecular and Cellular Responses of DNA Methylation and Thioredoxin System to Heat Stress in Meat-Type Chickens
}

\author{
Walid S. Habashy ${ }^{1,2, *(D)}$, Marie C. Milfort ${ }^{1}$, Romdhane Rekaya ${ }^{3}$ and Samuel E. Aggrey ${ }^{1, *(D)}$ \\ 1 NutriGenomics Laboratory, Department of Poultry Science, University of Georgia, Athens, GA 30602, USA; \\ milfort@uga.edu \\ 2 Department of Animal and Poultry Production, Damanhour University, Damanhour 22511, Egypt \\ 3 Department of Animal and Dairy Science, University of Georgia, Athens, GA 30602, USA; rrekaya@uga.edu \\ * Correspondence: walidh55@gmail.com or walid.habashi@agr.dmu.edu.eg (W.S.H.); saggrey@uga.edu (S.E.A.)
}

check for updates

Citation: Habashy, W.S.; Milfort,

M.C.; Rekaya, R.; Aggrey, S.E.

Molecular and Cellular Responses of DNA Methylation and Thioredoxin System to Heat Stress in Meat-Type Chickens. Animals 2021, 11, 1957.

https://doi.org/10.3390/ani11071957

Academic Editor: Ralf Einspanier

Received: 31 May 2021

Accepted: 28 June 2021

Published: 30 June 2021

Publisher's Note: MDPI stays neutral with regard to jurisdictional claims in published maps and institutional affiliations.

Copyright: (C) 2021 by the authors. Licensee MDPI, Basel, Switzerland. This article is an open access article distributed under the terms and conditions of the Creative Commons Attribution (CC BY) license (https:// creativecommons.org/licenses/by/ $4.0 /)$.
Simple Summary: Performance traits and mortality are negatively affected by heat stress. The responses of chickens to HS are extremely complex. Understanding of the molecular mechanism of DNA methylation and the TXN system under HS may provide a new strategy to mitigate the effect of HS. Based on our results, the thioredoxin pathway system under HS may provide clues to nutritional strategies to mitigate the effect of HS in meat-type chicken.

Abstract: Heat stress (HS) causes molecular dysfunction that adversely affects chicken performance and increases mortality. The responses of chickens to HS are extremely complex. Thus, the aim of this study was to evaluate the influence of acute and chronic exposure to HS on the expression of thioredoxin-peroxiredoxin system genes and DNA methylation in chickens. Chickens at $14 \mathrm{~d}$ of age were divided into two groups and reared under either constant normal temperature $\left(25^{\circ} \mathrm{C}\right)$ or high temperature $\left(35^{\circ} \mathrm{C}\right)$ in individual cages for 12 days. Five birds per group at one and 12 days post-HS were euthanized and livers were sampled for gene expression. The liver and Pectoralis major muscle were sampled for cellular analysis. mRNA expression of thioredoxin and peroxiredoxins (Prdx) 1, 3, and 4 in the liver were down-regulated at 12 days post-HS compared to controls. The liver activity of thioredoxin reductase (TXNRD) and levels of peroxiredoxin1 (Prdx1) at 12 days post-HS were significantly decreased. The results reveal that there was a significant decrease in DNA methylation at 12 days post HS in liver tissues. In conclusion, pathway of thioredoxin system under HS may provide clues to nutritional strategies to mitigate the effect of HS in meat-type chicken.

Keywords: heat stress; antioxidant; oxidative damage; thioredoxin; peroxiredoxin

\section{Introduction}

Heat waves and global climate change affect poultry negatively, so the understanding of how birds respond to high temperatures is important to the development of strategies to alleviate the lowered productivity and animal well-being. Heat stress (HS) impacts feed consumption, growth performance, feed conversion ratio, and mortality of broiler chickens [1-3]. We distinguish two categories of HS, the first being acute HS which refers to short-term rise in ambient temperature and the second being chronic HS which refers to a sustained long-term rise in ambient temperature. Acute HS is more likely under production environments, as the ambient temperatures tend to cool down during the nighttime whereas chronic HS can last anywhere from an entire day to a few weeks.

HS has been shown to be one of the causal factors of oxidative stress in broilers and in white leghorns [4-6]. Oxidative stress is caused by the overproduction of reactive oxygen species (ROS) due to disturbed homeostasis between pro-oxidant and antioxidant systems where the antioxidants are depressed compared to pro-oxidants $[7,8]$. ROS induce oxidative damage to biomolecules such as lipids, proteins, and nucleic acids resulting in lipid peroxidation, protein carbonyls, and oxidized guanine (8-oxo-dG) among others [9]. Oxidative 
stress also results in stable or heritable changes to gene expression that do not affect the DNA sequence, referred to as epigenetic changes, by altering DNA methylation $[10,11]$. The changes in DNA methylation induced by oxidative stress are mainly due to effects on the DNA methyltransferase enzymes that directly methylate DNA leading to both global hypomethylation and site-specific hypermethylation [12]. Our current knowledge about the level of DNA methylation in birds under HS remains scant.

Due to the fact that oxidative stress can seriously damage animal cells, even at the epigenetic level, there are multiple cellular defense systems to counteract or neutralize undesired ROS. Thioredoxin (TXN) and peroxiredoxin (Prdx) proteins are part of such systems. The Thioredoxin-Peroxiredoxin (TXN-Prdx) system scavenges hydrogen peroxides generated through mitochondrial cellular respiration and superoxide dismutase enzyme activity [13,14]. Prdx reduces $\mathrm{H}_{2} \mathrm{O}_{2}$ to water, becoming oxidized in the process on Cys 47, which then forms an intermolecular disulfide with Cys 170 [15]. Oxidized Prdx is then reduced back to its active form by TXN, which acts as an immediate electron donor [15]. Of the six peroxiredoxins identified in vertebrates, two (and Prdx5) are missing in chickens [16]. The ubiquitous TXN system is constituted of the proteins TXN and thioredoxin reductase (TR, TXNRD) and the cofactor NADPH [17]. TXN interacts with ROS damaged proteins such as oxidized Prdx through a pair of redox-active cysteines, thereby restoring their enzymatic activity by reducing oxidized active site cysteines [18]. The oxidized TXN is then reduced back to its active form as an electron donor by TXNRD, with NADPH being a required co-factor in the reaction [19]. The effects of elevated ambient temperatures on the TXN system genes are not clear. Understanding of the molecular mechanism of DNA methylation and the TXN system under HS may provide a new strategy to mitigate the effect of HS. Therefore, the objective of this study was to evaluate the influence of shortand long-term exposure to HS on DNA methylation and the gene expression and cellular activity of TXN-Prdx system in chicken liver and Pectoralis (P.) major muscle.

\section{Materials and Methods}

\subsection{Experimental Design and Animals}

The research herein was conducted under guidelines approved by the University of Georgia's institutional animal care and use committee. A total of 48 male Cobb500 (fast growing broilers) chickens were divided into two groups and raised in constant environments of either normal or high temperature $\left(25^{\circ} \mathrm{C}\right.$ or $\left.35^{\circ} \mathrm{C}\right)$ from days 14 to 26 of age in individual cages and fed a diet comprising $18.7 \% \mathrm{CP}$ and $3560 \mathrm{Kcal} \mathrm{ME} / \mathrm{K}$ ad libitum. At 1-day post HS (day 15) and 12 days post HS (day 26), tissues samples from the P. major muscle and liver were collected from 5 birds of each treatment and were directly placed in liquid nitrogen and stored later at $-86^{\circ} \mathrm{C}$.

\subsection{Determination of DNA Methylation ( $\mathrm{ng} / \mathrm{mL})$}

We extracted DNA from tissue samples of P. major and liver tissues with Trizol reagent (Invitrogen Corp., Carlsbad, CA, USA) following manufacturer's instructions and stored the extract at $-20{ }^{\circ} \mathrm{C}$ until further processing. DNA samples were then converted to single strands by heating to $95^{\circ} \mathrm{C}$ for $5 \mathrm{~min}$ followed by rapid chilling on ice. At that point, the DNA was digested with 5 units of nuclease P1 (Sigma, Saint Louis, MO, USA, item No. 8630). The $\mathrm{pH}$ was adjusted to 7.5-8.5 using $1 \mathrm{M}$ Tris and $5 \mu \mathrm{L}$ of alkaline phosphatase was then added and followed by incubation for $45 \mathrm{~min}$ at $37^{\circ} \mathrm{C}$ and boiling for $10 \mathrm{~min}$. The lysate was then stored at $4{ }^{\circ} \mathrm{C}$ until determination of methylation. The concentration of DNA methylation, measured with a commercial kit (Cayman Chemical Company, Ann Arbor, MI, USA, Item No. 589324), was determined spectrophotometrically using a Spectra Max 5 microplate reader (Molecular Devices, Sunnyvale, CA, USA) at $405 \mathrm{~nm}$.

\subsection{Gene Expression of the Thioredoxin System}

For gene expression analysis, liver samples were collected from 5 birds from each treatment at 1 and 12 days post HS and were immediately placed in liquid nitrogen and 
later stored at $-86^{\circ} \mathrm{C}$. Total RNA was extracted from liver tissues using Trizol reagent (Invitrogen Corp., Carlsbad, CA, USA) according to the manufacturer's instructions and purified with RNeasy mini kits (Qiagen, Valencia, CA, USA) according to the manufacturer's protocol. The RNA samples were suspended in RNase-free water and sample purity and concentration were measured on a NanoDrop spectrophotometer (Thermo Scientifc, Wilmington, DE, USA). For cDNA synthesis, $10 \mu \mathrm{g}$ of total RNA was reverse transcribed with high capacity cDNA reverse transcription kits according to manufacturer's protocol (Applied Biosystems, Carlsbad, CA, USA). The genes studied were: thioredoxin (TXN), thioredoxin reductase (TXNRD1), and peroxiredoxin-1 (PRDX1), peroxiredoxin-3 (PRDX3), and peroxiredoxin-4 (PRDX4).

Real-time PCR reactions were performed using the StepOnePlus (Applied Biosystems, Carlsbad, CA, USA). Final concentration of $47.1 \mathrm{ng} / \mu \mathrm{L} c \mathrm{DNA}$ served as a template in a $20 \mu \mathrm{L}$ PCR mixture containing a final concentration of $150 \mathrm{nM}$ from $10 \mu \mathrm{M}$ primer stocks and Fast SYBR Green Master Mix (Applied Biosystems, Carlsbad, CA, USA). The PCR conditions were $95^{\circ} \mathrm{C}$ for $20 \mathrm{~s}$, followed by 40 cycles of $95^{\circ} \mathrm{C}$ for $3 \mathrm{~s}$ and $60^{\circ} \mathrm{C}$ for $30 \mathrm{~s}$. In addition, at the end of each reaction, a melting temperature curve of every PCR reaction was determined. Data were analyzed according to the $2^{-\Delta \Delta \mathrm{Ct}}$ method [20] and were normalized by $\beta$-actin expression in each sample. The National Center for Biotechnology Information (NCBI) accession numbers, forward, reverse primers, and amplicon sizes used in this study are provided in Table 1.

Table 1. Primer pairs used to analyze gene expression by quantitative real time-PCR, and size of product.

\begin{tabular}{|c|c|c|c|c|}
\hline Gene Name and Symbol & Gene Bank Accession Number & Product Size (bp) & & Primer Sequence \\
\hline \multirow{2}{*}{$\begin{array}{c}\text { Thioredoxin } \\
\text { (TXN) }\end{array}$} & \multirow{2}{*}{ NM_205453.1 } & \multirow[b]{2}{*}{82} & Forward & 5'CATGCCAACATTCCAGTTCTAC $3^{\prime}$ \\
\hline & & & Reverse & $5^{\prime}$ GGTCTCTTCCAGCTTCTCTTT $3^{\prime}$ \\
\hline Thioredoxin reductase1 & \multirow{2}{*}{ NM_001030762.2 } & \multirow{2}{*}{126} & Forward & 5’AGAGCATGACCCAGCTTTATT 3' \\
\hline (TXNRD1) & & & Reverse & 5'GTGTGAAGGAAGCCTCAGTATC $3^{\prime}$ \\
\hline Peroxiredoxin 1 & \multirow{2}{*}{ NM_001271932.1 } & \multirow[b]{2}{*}{84} & Forward & $5^{\prime}$ GTACAGTGACAGAGCTGATGAA $3^{\prime}$ \\
\hline (PRDX1) & & & Reverse & 5'GCAAGGTGACAGAAGTGAGA3' \\
\hline Peroxiredoxin 3 & \multirow{2}{*}{ XM_426543.5 } & \multirow{2}{*}{95} & Forward & 5'GGAAATACCTCGTGCTCTTCTT 3' \\
\hline (PRDX3) & & & Reverse & 5'GTGGAACTCATTCGCTTTGTTAC 3' \\
\hline \multirow{2}{*}{$\begin{array}{l}\text { Peroxiredoxin } 4 \\
\quad(\text { PRDX4) }\end{array}$} & \multirow{2}{*}{ XM_416800.5 } & \multirow{2}{*}{100} & Forward & 5'GGACTCGGACCAATGAAGATT3' \\
\hline & & & Reverse & 5'CCCTAAGTGCATGTCCTTGAT 3' \\
\hline \multirow{2}{*}{$\beta$-actin } & \multirow{2}{*}{ NM_205518.1 } & \multirow{2}{*}{125} & Forward & 5'AGACATCAGGGTGTGATGGTTGGT3' \\
\hline & & & Reverse & 5'TCCCAGTTGGTGACAATACCGTGT3' \\
\hline
\end{tabular}

\subsection{Determination of Thioredoxin Reductase Activity ( $\mu \mathrm{mol} / \mathrm{min} / \mathrm{mL}$ )}

We homogenized approximately $0.2 \mathrm{~g}$ of tissue from P. major and liver in $1 \mathrm{~mL}$ cold $50 \mathrm{mM}$ potassium phosphate buffer, containing $1 \mathrm{mM}$ Ethylenediaminetetraacetic acid (EDTA) at $\mathrm{pH} 7$. Following centrifugation $(10,000 \times \mathrm{g}$ for $15 \mathrm{~min})$ at $4{ }^{\circ} \mathrm{C}$, the supernatants were stored frozen at $-86^{\circ} \mathrm{C}$ until analysis. We determined the activity of TXNRD (Cayman Chemical Company, Ann Arbor, MI, USA, Item No.10007892) spectrophotometrically at $405 \mathrm{~nm}$ using a Spectra Max 5 microplate reader by Molecular Devices (Sunnyvale, CA, USA).

\subsection{Determination of Peroxiredoxin1 Levels ( $\mathrm{pg} / \mathrm{mL}$ )}

Roughly $0.1 \mathrm{~g}$ of tissue from the P. major and liver were homogenized in $1 \mathrm{~mL}$ phosphate buffer saline, $\mathrm{pH} 7$ on ice and lysed by ultra-sonication. After centrifugation $(5000 \times g$ for $5 \mathrm{~min}$ ), the supernatants were collected for assaying Prdx1 (LifeSpan BioSciences, Washington DC, USA, Items No. LS-F19515) spectrophotometrically via SpectraMax5 microplate reader (Molecular Devices, Sunnyvale, CA, USA) at a wavelength of $450 \mathrm{~nm}$.

\subsection{Statistical Analysis}

Data analyses for TXNRD, Prdx1 and DNA methylation were carried out using PROC GLM in SAS [21]. Contrasts between the treatment levels were used to assess the statistical significance. 


\section{Results}

We investigated the effects of short and long term HS on the TXN-Prdx and the TXN systems in meat-type chickens. The expressions of TXN and TXNRD are presented in Figure 1.

(A) Day 1

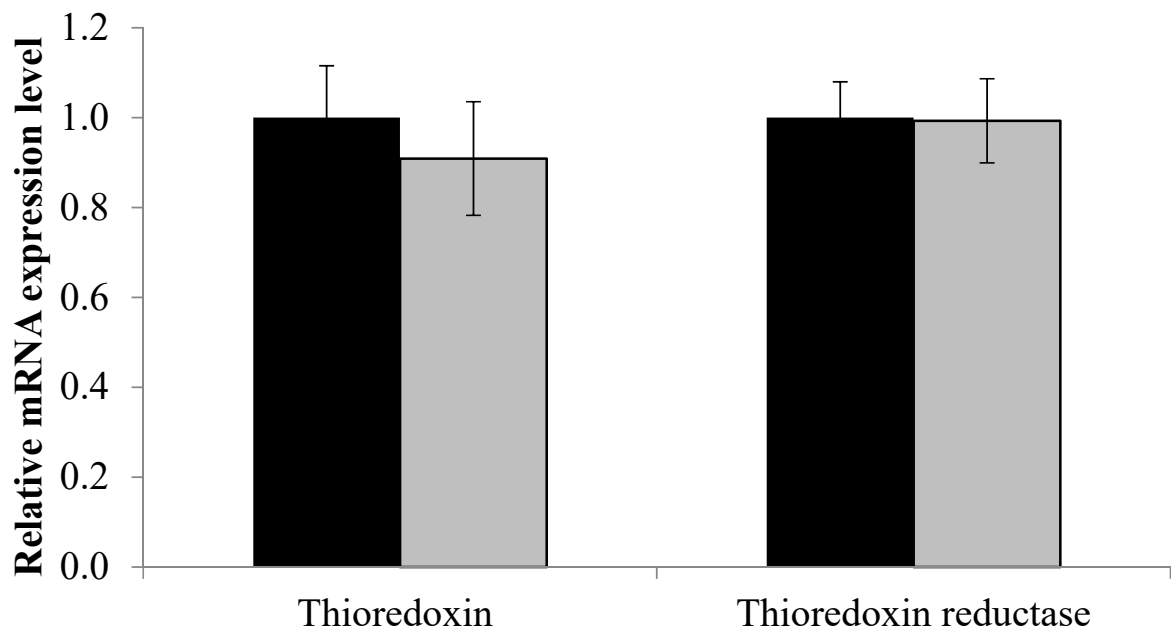

- Control $\square$ Heat Stress

(B) Day 12

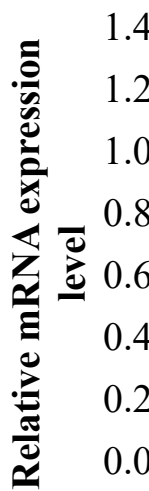

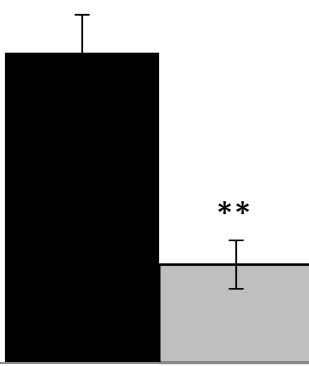

Thioredoxin

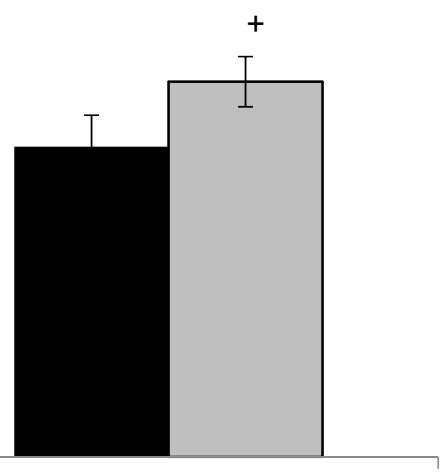

Thioredoxin reductase

- Control $\square$ Heat Stress

Figure 1. Effect of heat stress on thioredoxin and thioredoxin reductase mRNA at day 1 (A) and day 12 (B) in liver tissue of broiler. $\left({ }^{* *} p<0.01\right.$ and $\left.{ }^{+} p<0.1\right)$.

The relative levels of mRNA for the TXN gene in liver tissues was down-regulated after 1 and 12 days of exposure to HS and this down-regulation was statistically significant $(p<0.05)$ at the 12 day time point only. Meanwhile, the TXNRD was slightly up-regulated only at 12 days post HS, but this was not statistically significant $(p<0.1) \operatorname{Prdx1} \operatorname{Prdx} 3$, and $\operatorname{Prd} x 4$ expressions are presented in Figure 2.

Compared to controls, mRNA levels of $\operatorname{Prdx1} \operatorname{Prdx3}$, and $\operatorname{Prdx} 4$ were down-regulated at day $1(p<0.1)$ and day $12(p<0.05)$ of exposure to HS, but this down-regulation was statistically significant only at day 12 post-HS.

The cellular activity level of TXNRD, and the cellular level of Prdx1 and DNA methylation are presented in Figures 3-5. 
(A) Day 1

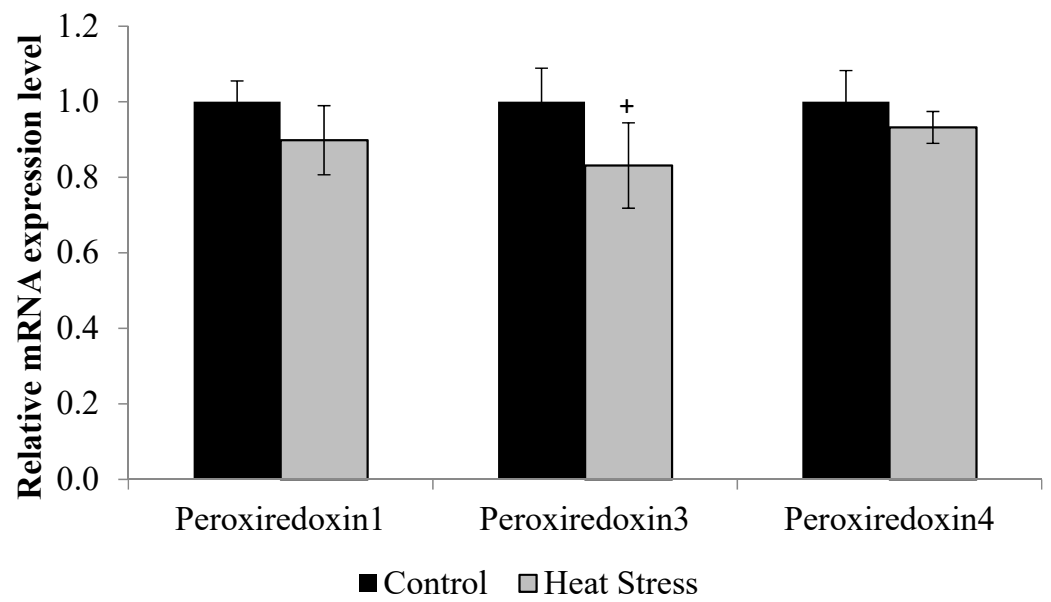

(B) Day 12

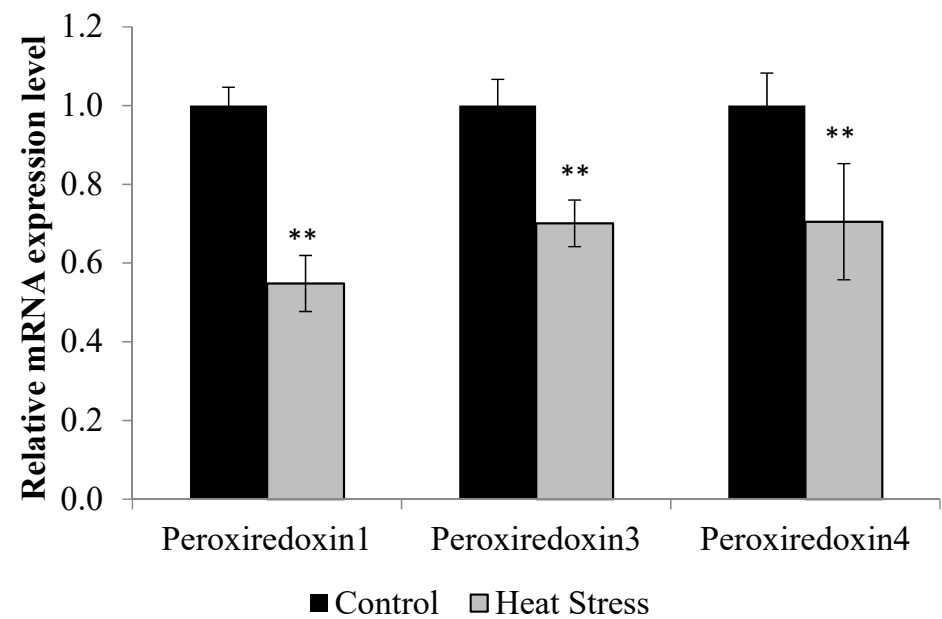

Figure 2. Effect of heat stress on peroxiredoxin 1, peroxiredoxin 3 , and peroxiredoxin $4 \mathrm{mRNA}$ at day 1 (A) and day 12 (B) in liver tissue of broiler. $\left(^{* *} p<0.01\right.$ and ${ }^{+} p<0.1$ ).

(A) Liver

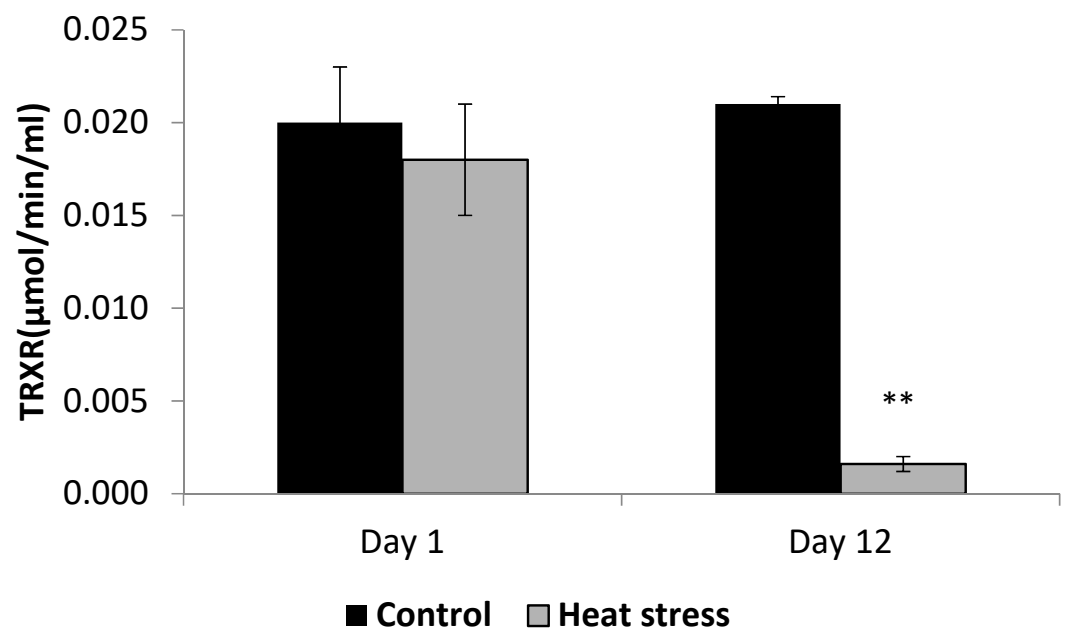

Figure 3. Cont. 
(B) Pectoralis major

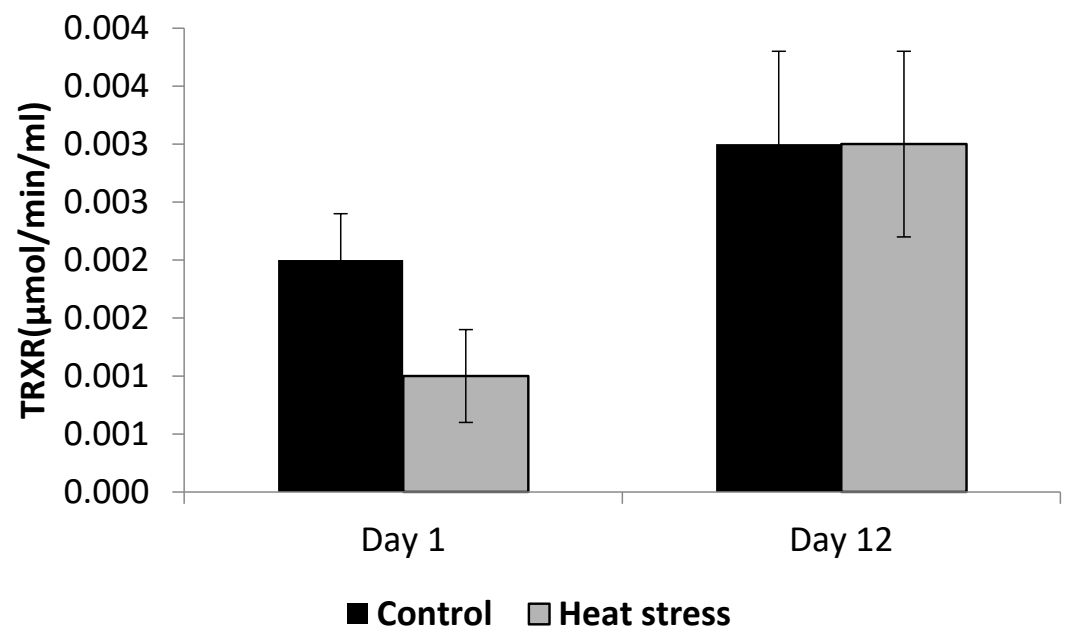

Figure 3. Effect of heat stress on thioredoxin reductase (TRXR) concentration in liver (A) and Pectoralis major $(\mathbf{B})$ tissue of broiler $\left.{ }^{* *} p<0.01\right)$.

(A) Liver

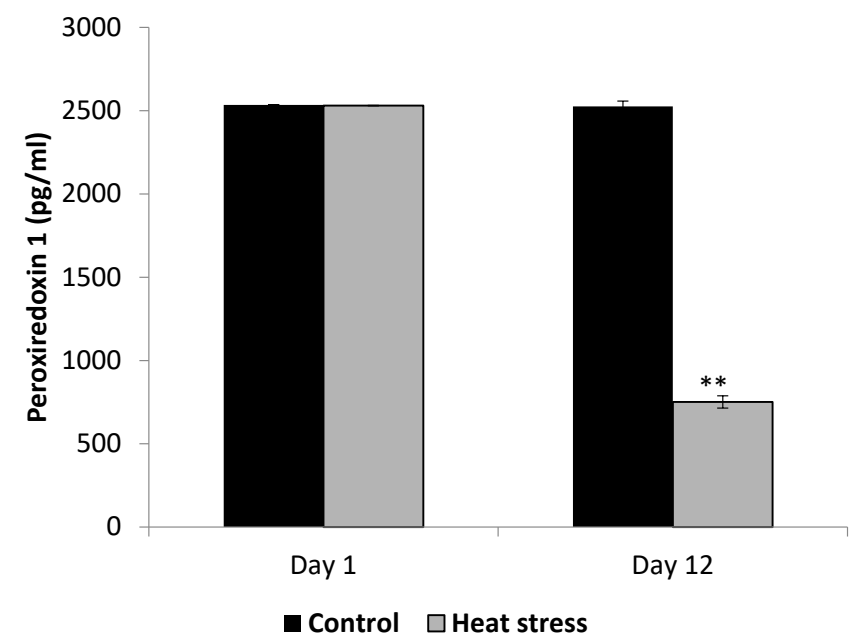

(B) Pectoralis major

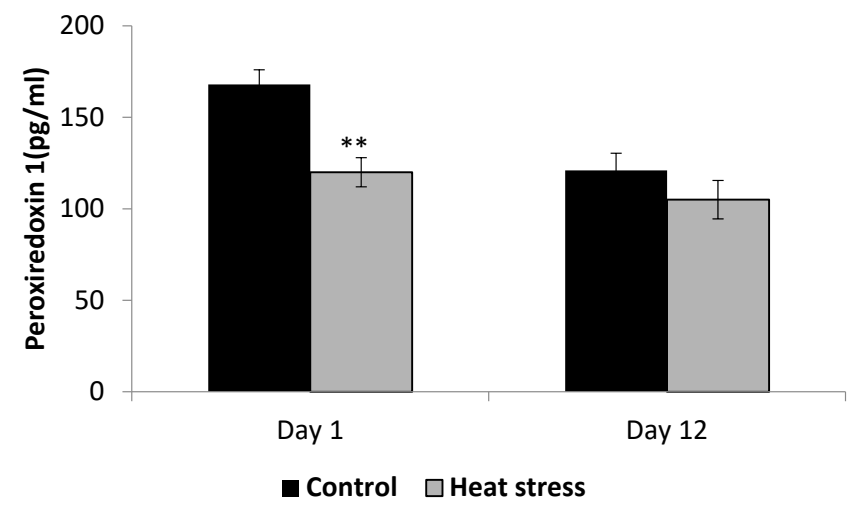

Figure 4. Effect of heat stress on peroxiredoxin1 concentration in liver (A) and Pectoralis major (B) tissue of broiler $(* * p<0.01)$. 
(A) Liver

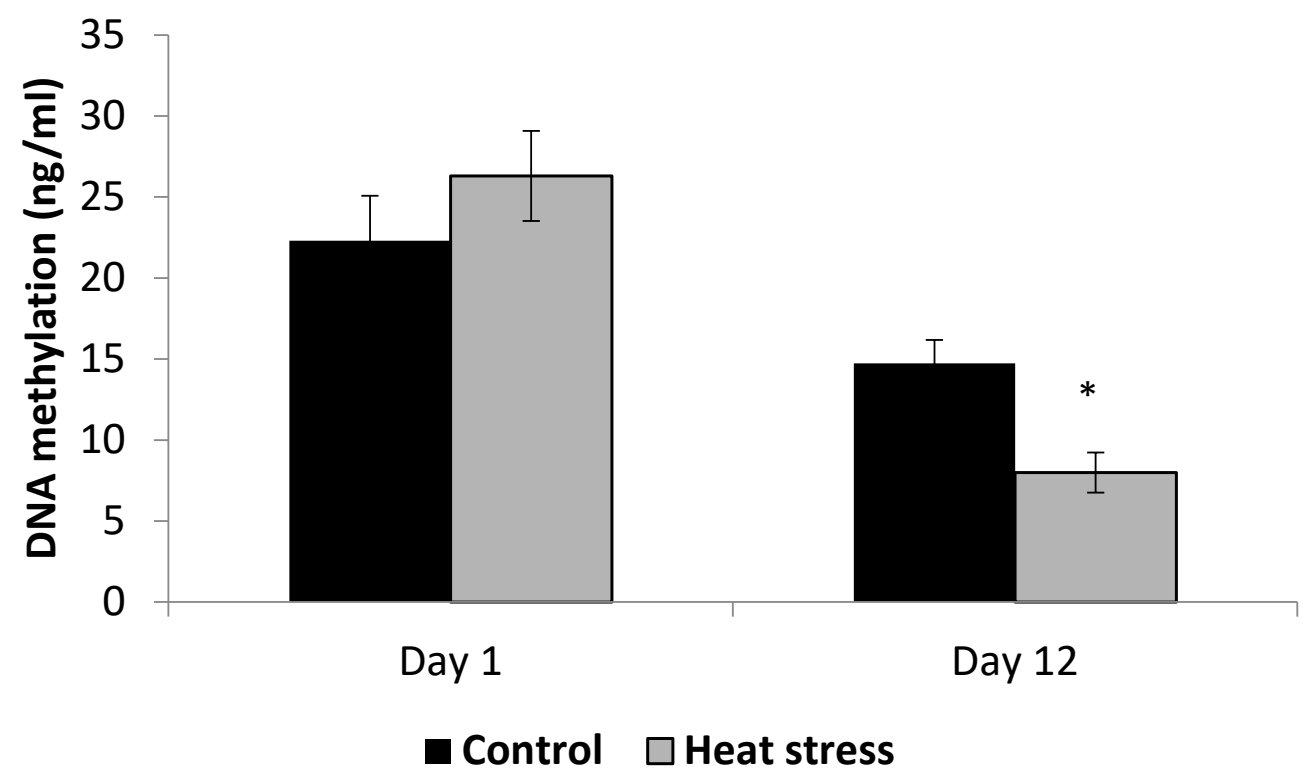

(B) Pectoralis major

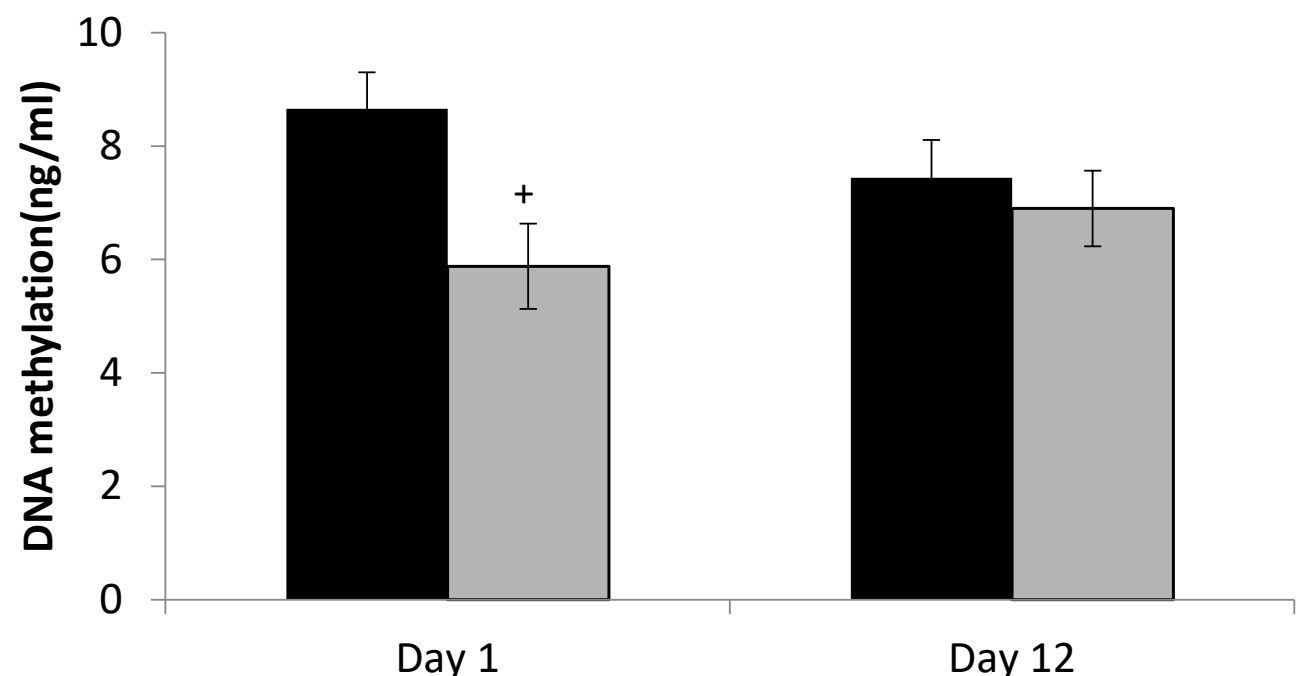

- Control $\square$ Heat stress

Figure 5. Effect of heat stress on DNA methylation in liver (A) and Pectoralis major (B) tissue of broiler $\left(^{*} p<0.05\right.$ and $+p<0.1)$.

The TXNRD activity levels decreased $(p<0.01)$ in the liver only at 12 days post-HS. There was no statistically significant difference in the TXNRD levels in the P. major both at 1 and 12 days post-HS (Figure 3). Additionally, heat stressed birds showed a decrease $(p<0.01)$ in the Prdx1 level at 12 days post-HS in the liver tissue and at 1 day post-HS in the P. major muscle (Figure 4). The concentration of methylated DNA was slightly but not significantly decreased after 1 day in P. major $(p>0.05)$ but it was significantly decreased in liver at 12 days in the stressed group $(p<0.05)$ (Figure 5). Meanwhile, after 1 day of HS, 
the quantity of DNA methylation in liver was higher in the heat stressed group than the control group, but not significant.

\section{Discussion}

HS is one of the most important burdens to the poultry industry, causing major economic losses. It is known that HS causes an adverse effect on the growth and production performance of poultry $[1,22]$. An understanding of the change in the expression of the TXN system and the cellular responses to HS could offer a new strategy to mitigate the effect of HS.

\subsection{Heat Stress and Expression of the Thioredoxin System}

The TXN system consisting of TXN, and TXNRD plays an important role in oxidative and nitrosative stress mitigation through reducing and scavenging peroxides and free radicals [23]. TXN reduces disulfide bonds resulting from protein oxidation in a reaction that results in oxidized TXN, which is then turned over by TXNRD using NADPH [24]. This system, in combination with Prdx activity, plays an important role in consuming mitochondrial $\mathrm{H}_{2} \mathrm{O}_{2}$ [25]. Data on the regulation of TXN, TXNRD, Prdx1, Prdx3, and Prdx4 in both acute and chronic HS is scant. In the current study, the TXN, $\operatorname{Prdx1}, \operatorname{Prdx} 3$, and $\operatorname{Prd} 44$ genes mRNA expressions were down-regulated at day 12 post-HS. Thus, chronic HS causes changes in the TXN-Prdx system that are not apparent in acute HS. This might be due to the increase in $\mathrm{H}_{2} \mathrm{O}_{2}$.

Treatment of SH-SY5Y human neuroblastoma cells with different concentrations of $\mathrm{H}_{2} \mathrm{O}_{2}$ led to decreased mRNA expression of TXN, which was exacerbated by induced mitochondrial dysfunction [26]. Thus, the increased cellular $\mathrm{H}_{2} \mathrm{O}_{2}$ as a result of HS may be responsible for the down-regulation of TXN. In the current work, TXNRD expression is somewhat increased in the heat stressed group at day 12 post-HS, perhaps as a compensatory mechanism in the face of increased oxidative stress. However, the significant down-regulation of TXN shown in the heat stressed group could limit the substrate available for reaction of TXNRD and thus limit its protective abilities.

Peroxiredoxins are ubiquitous cellular enzymes that scavenge peroxide and peroynitrite [27]. The mRNA expression of $\operatorname{Prd} 1 \times 1, \operatorname{Prdx} 3$, and $\operatorname{Prd} 44$ significantly decreased at 12 days post-HS. Kang et al. showed that there are six isoforms of Prdx [28]. Prdxs1-4 are TXN peroxidases that require TXN as an electron donor to remove $\mathrm{H}_{2} \mathrm{O}_{2}$ and contain two conserved cysteine residues that participate in the reaction [29]. It is apparent that exposure of chicks to HS leads to mRNA expression changes in TXN and elicits downregulation of $\operatorname{Prd} x 1,3$, and 4 at day 12 post-HS. Hwang et al. showed that $\operatorname{Prd} x 3$ increased in neurons 1 day post ischemia and in glia 3 days post ischemia related to removal of ROS and phagocytic processes [30]. They also showed increases in TXN2 30 min post ischemia, which decreases $6 \mathrm{~h}$ later and increases again 1 day post ischemia indicating time sensitivity of TXN system changes. The decrease in TXN was correlated with cell death. Infusion with Prdx3 alone or in combination with TXN2 protects against ischemic damage and reduces lipid peroxidation. The results of Hwang et al. [30] and that of the current study may indicate acute compensation followed by long-term decompensation, leading to decreased antioxidant activity and may be one reason why HS causes decreases in performance. These issues may be remedied by antioxidant replacement and require further study.

\subsection{Heat Stress and Cellular Activity of the Thioredoxin System}

HS has been shown to elevate the level of ROS in several animal models, and the TXN-Prdx system is one of the main hydrogen peroxide-scavenging systems used by cells $[13,14,31]$. TXNRD enzymes catalyze the reduction of TXN to restore its antioxidant activity. In the current study, the liver TXNRD activity and Prdx1 levels decreased under chronic HS but not under acute stress. The TXNRD and Prdx1 response to HS may depend on the duration of the stress and also the tissue examined. Based on our results, it seems 
that liver tissue TXN-Prdx system is more affected by chronic HS than the muscle, and this may be due to the liver's larger role in scavenging free radicals.

\subsection{Heat Stress and DNA Methylation}

This study also involved measurement of the levels of DNA methylation, because DNA methylation plays a key role in the regulation of gene expression, and chronic oxidative stress is known to change the expression of DNA methylation regulators $[32,33]$. The TXN system genes have increased DNA methylation levels in the liver of Wilson's disease patients and in the disease mouse model where copper induced oxidative stress is a major factor [34]. In the current study, with an increase in the duration of exposure to HS, the concentrations of global DNA methylation were down-regulated significantly in the liver. Meanwhile, in P. major, the concentrations of DNA methylation were not significantly different after 1 or 12 days of HS than the control. HS-induced oxidative stress may result in global hypomethylation but hypermethylation of specific genes. The methylation status of antioxidant genes under HS needs further study. Mordaunt et al. [34] also showed that choline supplementation can increase TXN and Prdx gene expression in mouse liver, suggesting that choline supplementation could be pursued as a remedy for the decreased expression of these two genes we studied in the livers of chronically heat stressed birds.

\section{Conclusions}

There are several studies that have evaluated very short-term effects of HS. In the current study, we show that molecular responses of TXN-Prdx system to short term exposure to HS may be different from that of relatively long term. We show that exposure of broilers to HS for longer times leads to decreased gene expression of TXN, Prdx1, Prdx3, and Prdx4. Furthermore, HS decreases the level of TXNRD, Prdx1, and DNA methylation in liver. Taken together, we suggest that TXNRD, Prdx1 and DNA methylation can be used as biomarkers of oxidative damage in meat-type chickens under chronic HS. The implications of the dynamics of genes in the ROS and TXN-Prdx pathways may provide insight into nutritional intervention strategies (e.g., supplementation of antioxidants) when birds are exposed to HS.

Author Contributions: Conceptualization, S.E.A.; methodology; formal analysis, and data curation, W.S.H. and M.C.M.; writing—original draft preparation, W.S.H.; writing—review and editing, M.C.M., R.R. and S.E.A. All authors have read and agreed to the published version of the manuscript.

Funding: This work is supported by Advanced Technologies for the Genetic Improvement of Poultry (project accession no. 1025875) from the USDA National Institute of Food and Agriculture.

Institutional Review Board Statement: The study was conducted according to the guidelines of the institutional animal care and use committee of the University of Georgia (protocol code A2018 09-002-Y2-A0 and 10-18-2020).

Data Availability Statement: The datasets generated during and/or analyzed during the current study are available from the corresponding author on reasonable request.

Conflicts of Interest: The authors declare no conflict of interests.

\section{References}

1. Habashy, W.S.; Milfort, M.C.; Adomako, K.; Attia, Y.A.; Rekaya, R.; Aggrey, S.E. Effect of heat stress on amino acid digestibility and transporters in meat-type chickens. Poult. Sci. 2017, 96, 2312-2319. [CrossRef]

2. Habashy, W.S.; Milfort, M.C.; Rekaya, R.; Aggrey, S.E. Expression of genes that encode cellular oxidant/antioxidant systems are affected by heat stress. Mol. Biol. Rep. 2018, 45, 389-394. [CrossRef]

3. Liu, L.; Ren, M.; Ren, K.; Jin, Y.; Yan, M. Heat stress impacts on broiler performance, a systematic review and meta-analysis. Poult. Sci. 2020, 99, 6205-6211. [CrossRef] [PubMed]

4. Lin, H.; Decuypere, E.; Buyse, J. Acute heat stress induces oxidative stress in broiler chickens. Comp. Biochem. Physiol. Part A 2006, 144, 11-17. [CrossRef] [PubMed]

5. Mujahid, A.; Akiba, Y.; Toyomizu, M. Acute heat stress induces oxidative stress and decrease adaptation in young White Leghorn cockerels by down regulation of avian uncoupling protein. Poult. Sci. 2007, 86, 364-371. [CrossRef] 
6. Habashy, W.S.; Milfort, M.C.; Rekaya, R.; Aggrey, S.E. Cellular antioxidant enzyme activity and biomarkers for oxidative stress are affected by heat stress. Int. J. Biometeorol. 2019, 63, 1569-1584. [CrossRef]

7. Bruskov, V.I.; Malakhova, L.V.; Masalimov, Z.K.; Chernikov, A.V. Heat induced formation of reactive oxygen species and 8-oxoguanine, a biomarker of damage to DNA. Nucleic Acids Res. 2002, 30, 1354-1363. [CrossRef]

8. Ganaie, A.H.; Shanker, G.; Bumla, N.A.; Ghasura, R.S.; Mir, N.A. Biochemical and physiological changes during thermal stress in bovines. J. Vet. Sci. Technol. 2013, 4, 126.

9. Davies, K.J. Oxidative stress: The paradox of aerobic life. Biochem. Soc. Symp. 1995, 61, 1-13. [PubMed]

10. Cerda, S.; Weitzman, S.A. Influence of oxygen radical injury on DNA methylation. Mutat. Res. 1997, 386, 141-152. [CrossRef]

11. Goldberg, A.D.; Allis, C.D.; Bernstein, E. Epigenetics, a landscape takes shape. Cell 2007, 128, 635-638. [CrossRef]

12. García-Guede, Á.; Vera, O.; Ibáñez-de-Caceres, I. When Oxidative Stress Meets Epigenetics, Implications in Cancer Development. Antioxidants 2020, 9, 468. [CrossRef]

13. Murphy, M.P. Mitochondrial thiols in antioxidant protection and redox signaling, distinct roles for glutathionylation and other thiol modifications. Antioxid. Redox Signal. 2012, 16, 476-495. [CrossRef]

14. Mailloux, R.J.; McBride, S.L.; Harper, M.E. Unearthing the secrets of mitochondrial ROS and glutathione in bioenergetics. Trends Biochem. Sci. 2013, 38, 592-602. [CrossRef]

15. Rhee, S.G.; Kang, S.W.; Chang, T.S.; Jeong, W.; Kim, K. Peroxiredoxin, a novel family of peroxidases. IUBMB Life 2001, 52, 35-41. [CrossRef] [PubMed]

16. Pirson, M.; Clippe, A.; Knoops, B. The curious case of peroxiredoxin-5, what its absence in aves can tell us and how it can be used. BMC Evol. Biol. 2018, 18, 18. [CrossRef]

17. Ghareeb, H.; Metanis, N. The Thioredoxin System, A Promising Target for Cancer Drug Development. Chemistry 2020, 26, 10175-10184. [CrossRef] [PubMed]

18. Fernando, M.R.; Nanri, H.; Yoshitake, S.; Nagata-Kuno, K.; Minakami, S. Thioredoxin regenerates proteins inactivated by oxidative stress in endothelial cells. Eur. J. Biochem. 1992, 209, 917-922. [CrossRef] [PubMed]

19. Williams, C.H.; Arscott, L.D.; Müller, S.; Lennon, B.W.; Ludwig, M.L.; Wang, P.F.; Veine, D.M.; Becker, K.; Schirmer, R.H. Thioredoxin reductase two modes of catalysis have evolved. Eur. J. Biochem. 2000, 267, 6110-6117. [CrossRef] [PubMed]

20. Livak, K.J.; Schmittgen, T.D. Analysis of relative gene expression data using real time quantitative PCR and the $2^{-\Delta \Delta C t}$ method. Methods 2001, 25, 402-408. [CrossRef] [PubMed]

21. SAS Institute. SAS ${ }^{\circledR}$ User's Guide, version 9.4; Statistics; SAS Institute Inc.: Cary, NC, USA, 2011.

22. Rimoldi, S.; Lasagna, E.; Sarti, F.M.; Marelli, S.P.; Cozzi, M.C.; Bernardini, G.; Terova, G. Expression profile of six stress-related genes and productive performances of fast and slow growing broiler strains reared under heat stress conditions. Meta Gene 2015, 31, 17-25. [CrossRef] [PubMed]

23. Lee, S.; Kim, S.M.; Lee, R.T. Thioredoxin and thioredoxin target proteins, from molecular mechanisms to functional significance. Antioxid. Redox Signal. 2013, 18, 1165-1207. [CrossRef] [PubMed]

24. Mailloux, R.J. Mitochondrial antioxidants and the maintenance of cellular hydrogen peroxide levels. Oxid. Med. Cell Longev. 2018, 2018, 7857251. [CrossRef]

25. Lopert, P.; Patel, M. Brain mitochondria from DJ-1 knockout mice show increased respiration-dependent hydrogen peroxide consumption. Redox Biol. 2014, 2, 667-672. [CrossRef] [PubMed]

26. Ding, H.; Gao, J.; Zhu, Z.; Xiong, Y.; Liu, J. Mitochondrial Dysfunction Enhances Susceptibility to Oxidative Stress by DownRegulation of Thioredoxin in Human Neuroblastoma Cells. Neurochem. Res. 2008, 33, 43-50. [CrossRef]

27. Perkins, A.; Nelson, K.J.; Parsonage, D.; Poole, L.B.; Karplus, P.A. Peroxiredoxins, Guardians Against Oxidative Stress and Modulators of Peroxide Signaling. Trends Biochem. Sci. 2015, 40, 435-445. [CrossRef]

28. Kang, S.W.; Chae, H.Z.; Seo, M.S.; Kim, K.; Baines, I.C.; Rhee, S.G. Mammalian peroxidoxin isoforms can reduce hydrogen peroxide generated in response to growth factors and tumor necrosis factor- alpha. J. Biol. Chem. 1998, 273, 6297-6302. [CrossRef] [PubMed]

29. Nonn, L.; Berggren, M.; Powis, G. Increased expression of mitochondrial peroxiredoxin-3 (thioredoxin peroxidase-2) protects cancer cells against hypoxia and drug-induced hydrogen peroxide-dependent apoptosis. Mol. Cancer Res. 2003, 1, 682-689.

30. Hwang, I.K.; Yoo, K.Y.; Kim, D.W.; Lee, C.H.; Choi, J.H.; Kwon, Y.G.; Kim, Y.M.; Choi, S.Y.; Won, M.H. Changes in the expression of mitochondrial peroxiredoxin and thioredoxin in neurons and glia and their protective effects in experimental cerebral ischemic damage. Free Radic. Biol. Med. 2010, 48, 1242-1251. [CrossRef]

31. Kikusato, M.; Toyomizy, M. Crucial role of membrane potential in heat stress-induced overproduction of reactive oxygen species in avian skeletal muscle mitochondria. PLoS ONE 2013, 8, e64412. [CrossRef]

32. Gao, F.; Luo, Y.; Li, S.; Li, J.; Lin, L.; Nielsen, A.l.; Sorensen, C.B.; Vaita, G.; Wang, J.; Zhang, X.; et al. Comparison of gene expression and genome-wide DNA methylation profiling between phenotypically normal cloned pigs and conventionally bred controls. PLoS ONE 2011, 6, e25901. [CrossRef] [PubMed]

33. Mahalingaiah, P.K.; Ponnusamy, L.; Singh, K.P. Oxidative stress-induced epigenetic changes associated with malignant transformation of human kidney epithelial cells. Oncotarget 2017, 8, 11127-11143. [CrossRef] [PubMed]

34. Mordaunt, C.E.; Shibata, N.M.; Kieffer, D.A.; Czlonkowska, A.; Litwin, T.; Weiss, K.H.; Gotthardt, D.N.; Olson, K.; Wei, D.; Cooper, S.; et al. Epigenetic changes of the thioredoxin system in the tx-j mouse model and in patients with Wilson disease. Hum. Mol. Genet. 2018, 27, 3854-3869. [CrossRef] [PubMed] 